\title{
The role of intolerance of uncertainty in the acquisition and extinction of reward
}

\section{Article}

Published Version

Creative Commons: Attribution 4.0 (CC-BY)

Open Access

Morriss, J., Biagi, N. ORCID: https://orcid.org/0000-00027119-0767, Lonsdorf, T. B. and Andreatta, M. (2021) The role of intolerance of uncertainty in the acquisition and extinction of reward. The European Journal of Neuroscience, 53 (9). pp. 3063-3071. ISSN 0953-816X doi: https://doi.org/10.1111/ejn.15173 Available at https://centaur.reading.ac.uk/98181/

It is advisable to refer to the publisher's version if you intend to cite from the work. See Guidance on citing.

To link to this article DOI: http://dx.doi.org/10.1111/ejn.15173

Publisher: Blackwell Publishing

All outputs in CentAUR are protected by Intellectual Property Rights law, including copyright law. Copyright and IPR is retained by the creators or other copyright holders. Terms and conditions for use of this material are defined in the End User Agreement.

\section{www.reading.ac.uk/centaur}

\section{CentAUR}


Central Archive at the University of Reading

Reading's research outputs online 


\title{
The role of intolerance of uncertainty in the acquisition and extinction of reward
}

\author{
Jayne Morriss $^{1}$ (D) | Nicolo Biagi ${ }^{1}$ | Tina B. Lonsdorf ${ }^{2}$ | Marta Andreatta $^{3}$ (ID
}

${ }^{1}$ Centre for Integrative Neuroscience and Neurodynamics, School of Psychology and Clinical Language Sciences, University of Reading, Reading, UK

${ }^{2}$ Institute for Systems Neuroscience, University Medical Center HamburgEppendorf, Hamburg, Germany ${ }^{3}$ Department of Psychology, Education \& Child Studies, Erasmus University Rotterdam, Rotterdam, The Netherlands

\section{Correspondence}

Jayne Morriss, Centre for Integrative Neuroscience and Neurodynamics, School of Psychology and Clinical Language Sciences, University of Reading, Earley Gate, Whiteknights Campus, RG6 6AH Reading, UK.

Email: j.e.morriss@ reading.ac.uk

\section{Funding information}

Economic and Social Research Council, Grant/Award Number: ES/R01145/1;

National Alliance for Research on

Schizophrenia and Depression,

Grant/Award Number: 27567

\begin{abstract}
Individuals, who score high in self-reported intolerance of uncertainty (IU), tend to find uncertainty anxiety-provoking. IU has been reliably associated with disrupted threat extinction. However, it is unclear whether IU would be related to disrupted extinction to other arousing stimuli that are not threatening (i.e., rewarding). We addressed this question by conducting a Pavlovian reward conditioning task with acquisition and extinction training phases $(n=58)$. In the Pavlovian reward conditioning task, we recorded liking ratings, skin conductance response (SCR), and corrugator supercilii activity (i.e., brow muscle indicative or negative and positive affect) to learned reward (CS+) and neutral (CS-) cues. Typical patterns of reward acquisition and extinction training were observed for liking ratings. There was evidence for conditioning in SCR during the extinction training phase but not the acquisition training phase. However, no evidence of conditioning in either the acquisition or extinction training phase was observed for the corrugator supercilii. IU was not related to any measures during the acquisition or extinction training phases. Taken together, these results suggest that the current Pavlovian reward conditioning task was not sufficient for eliciting a reliable conditioned reward response, and therefore, further research with optimized reward conditioning designs are required to test whether IU-related deficits occur during the extinction of reward.
\end{abstract}

\section{K E Y W O R D S}

acquisition, extinction, intolerance of uncertainty, reward, skin conductance

\section{INTRODUCTION}

Individuals, who score high in self-reported intolerance of uncertainty (IU), tend to find uncertainty negative (i.e., stressful, distressing; Carleton, 2016a, 2016b). IU is a transdiagnostic risk factor, as high levels of self-reported IU are observed in a number of mental health disorders (Kesby et al., 2017; McEvoy \& Mahoney, 2012). Recent research has shown individuals high in IU, relative to individuals low in IU, to display heightened physiological and neural activity to uncertain threat and reward (for review, see Tanovic et al., 2018).

The majority of the literature has, so far, focused on how IU is involved in the processing of uncertain threat. Research suggests that IU may play a critical role in associative threat learning (for review see Tanovic et al., 2018). During threat acquisition training with partial reinforcement, there is some evidence that individuals with high IU display greater startle blink to learned threat versus safety cues (Chin et al., 2016; 
Sjouwerman et al., 2020). However, a number of studies have not found relationships between IU and physiological measures during threat acquisition training with partial reinforcement (Dunsmoor et al., 2015; Lucas et al., 2018; Morriss, 2019; Morriss et al., 2020). Notably, the relationship between IU and threat extinction training is more consistent: during threat extinction training, individuals with high IU have been shown to display greater skin conductance, pupil dilation, and amygdala activity to learned threat versus safety cues (Morriss et al., 2015, Morriss, Christakou, et al., 2016, Morriss, Macdonald, et al., 2016; Morriss \& van Reekum, 2019; Wake et al., 2021).

During threat extinction training, the conditioned stimulus (CS+: i.e., a shape) is presented without the associated unconditioned stimulus (US: i.e., shock or loud noise). This change in contingency may result in two different interpretations for the CS+ (Bouton, 2002): the CS+ may be interpreted either as an uncertain threat cue or as a safety cue. It has been suggested that the uncertainty surrounding the meaning of the CS+ during extinction is what maintains the conditioned response in individuals with high IU (Dunsmoor et al., 2015; Morriss \& van Reekum, 2019; Morriss et al., 2019). This explanation is in line with a current definition of IU, which postulates that individuals with high IU have central beliefs that information is missing or omitted, which in turn sustains the perception of uncertainty and associated heightened physiological arousal (Carleton, 2016b, p. 31).

From the existing literature, it is evident that individuals with higher IU have difficulty extinguishing the threat association, even when mild (Morriss et al., 2019). However, gaps still remain in the literature as to what experimental parameters induce disrupted extinction in individuals with high IU. For example, is disrupted extinction in individuals with higher IU limited to situations with uncertain threat or can it occur with other uncertain stimuli with arousing properties (i.e., rewarding)? Indeed, there is a small emerging literature on the role of IU in the processing of uncertain reward. During the anticipation of uncertain reward, individuals with high IU display greater anterior insula activity (Gorka et al., 2016) and altered electroencephalogram and event-related potential responses (Nelson et al., 2014, 2016). Furthermore, a handful of decision-making studies have demonstrated that individuals with high IU are more likely to choose immediate smaller rewards over waiting for larger uncertain rewards (Carleton et al., 2016; Luhmann et al., 2011; Tanovic, Hajcak, et al., 2018). Based on the aforementioned evidence, it is possible that individuals with high IU may also display differences during the acquisition and extinction of reward associations.

Given that IU is transdiagnostic and that associative learning principles underpin current exposure therapies (Craske et al., 2014), examining whether IU is related to the acquisition and extinction of reward may provide crucial information relevant to the pathology and treatment of a number of mental health disorders that have a reward component and rely on exposure therapy such as substance abuse and eating disorders (Koskina et al., 2013; Marissen et al., 2007).

Here, we conducted a Pavlovian reward conditioning task to assess the relationship between individual differences in self-reported IU and conditioned reward responses. We measured skin conductance response, corrugator supercilii activity (i.e., brow muscle indicative of negative or positive affect) and liking ratings of the $\mathrm{CS}+$ and $\mathrm{CS}-$ during the acquisition and extinction training phases. We used secondary rewards (i.e., money) as unconditioned stimuli and visual shape stimuli as conditioned stimuli, in line with previous conditioning research (Andreatta \& Pauli, 2015, 2019; Ebrahimi et al., 2019; Kruse et al., 2020; Kruse et al., 2018; Kruse et al., 2017; Tapia León et al., 2018; Tapia León et al., 2019; van den Akker et al., 2017). We used a 50\% reinforcement rate during acquisition training to prolong the effect of conditioning (Bouton, 2002) and induce greater uncertainty during extinction similar to our previous work (Morriss, 2019; Wake et al., 2020).

We hypothesized that during reward acquisition training, skin conductance responding and liking ratings would be higher, and corrugator supercilii activity would be lower, to the learned reward (CS+) versus neutral (CS-) cues, indicative of conditioned responding (Andreatta \& Pauli, 2015; Ebrahimi et al., 2019; Kruse et al., 2017; Kruse et al., 2018; Kruse et al., 2020; Tapia León et al., 2018; Tapia León et al., 2019; van den Akker et al., 2017; Wardle et al., 2018). Given the lack of IU-related findings for the acquisition training phase in past research, we did not have any specific IU hypotheses for the acquisition training phase. We hypothesized that if IU-related effects during extinction training are driven by the arousingness of an uncertain stimulus, then higher IU, relative to lower $\mathrm{IU}$, will be associated with larger conditioned responding to $\mathrm{CS}+$ versus $\mathrm{CS}-$ cues during reward extinction training. We tested the specificity of IU effects by controlling for trait anxiety, assessed by the State-Trait Inventory for Cognitive and Somatic Anxiety (STICSA; Ree et al., 2008). We selected the STICSA because it is thought to be a purer measure of anxiety, compared to other trait anxiety measures which also feature depressive symptomology (Grös et al., 2007).

\section{2 | METHOD}

\section{1 | Participants}

Fifty-eight participants were recruited from the University of Reading and local area through the use of advertisements and word of mouth (Sex: 29 female, 29 male; $M_{\text {age }}=25.42$ years, $S D_{\text {age }}=4.70$ years, range $=18-35$ years; Ethnicity: 32 White, 16 Asian, 4 not specified, 3 Mixed, 2 Black, and 1 Arab; Sexual 
Orientation: 45 Heterosexual, 10 not specified, and 3 Sexual Minorites [homosexual/bisexual]). We recruited participants who were between the ages of 18 and 35 years. No other exclusion criteria was used for recruitment. Participants were paid $£ 5$ remuneration for their time. Participants provided written informed consent. The procedure was reviewed and accepted by the University of Reading Research Ethics Committee.

Multilevel models (MLM) were used to analyze experimental data, where IU and STICSA scores were entered into the analysis as continuous predictor variables. Due to the complexity of MLMs, there is no agreed upon method for calculating power and estimating sample size for MLM (Peugh, 2010). Therefore, appropriate sample sizes were estimated based upon power analyses using a repeated measures ANCOVA. The sample size of this study was based on a power analysis using the average effect size $\left(\eta_{\mathrm{p}}^{2}=0.16\right)$ taken from Stimulus $\times$ Time $\times$ IU interactions for SCR magnitude from five previous experiments (4/5 with significant effects of IU; Morriss et al., 2015, Morriss, Christakou, et al., 2016, Morriss, Macdonald, et al., 2016; Morriss \& van Reekum, 2019). The following parameters were used in $\mathrm{G}^{*}$ Power 3.1.9.7: effect size $f=0.40$ (converted from $\eta_{\mathrm{p}}^{2}=0.16$ and rounded down), $\alpha$ error probability $=0.05$, Power $(1-\beta$ error probability $)=0.8$, numerator $d f=1$, number of covariates $=2$ (IU, STICSA). The total sample size suggested was an $n=52$. Due to nonresponding in SCR (typically $5 \%-10 \%$ of sample), we attempted to increase statistical power by recruiting a total $n$ of 60 . However, due to the Covid-19 pandemic, recruitment was interrupted, leaving the current study with a total sample size of $n=58$.

\section{2 | Materials}

The conditioning task was designed using E-Prime 2.0 software (Psychology Software Tools Ltd, Pittsburgh, PA). Participants were seated approximately $60 \mathrm{~cm}$ from the screen. Visual stimuli were yellow and blue squares displayed on a black background. To represent monetary reward, the presentation of a " $£$ " symbol and a 1,000-ms $70 \mathrm{~dB}$ sound of coins dropping served as the US.

The task comprised three phases: acquisition, an immediate extinction training, and reinstatement (not included here). During acquisition training, one of the squares was paired with the US $50 \%$ of the time (CS+), whereas the other square was presented alone (CS-). During extinction training, the squares were presented in the absence of the US. There was no explicit break between the acquisition and extinction training phases, although there was a rating period between (see below). Conditioning contingencies (i.e., assignment of the CS+ and CS-) were counterbalanced. We did not include a habituation phase.

The acquisition training phase consisted of 16 trials (4 $\mathrm{CS}+$ paired, $4 \mathrm{CS}+$ unpaired, $8 \mathrm{CS}-$ ). The extinction training phase comprised of 32 trials (16 CS+ and $16 \mathrm{CS}-$ ), where early is defined as the first $8 \mathrm{CS}+/ \mathrm{CS}-$ trials, and late is defined as the last $8 \mathrm{CS}+/ \mathrm{CS}-$ trials. Experimental trials were pseudo-randomized such that the first trial of acquisition training was always a $\mathrm{CS}+$ paired and then after each trial type could only be played 3 times in a row. The CS's (squares) were presented for a total of $6 \mathrm{~s}$. After this, a blank black screen was presented for 8-12 s and served as the intertrial interval. During reinforced trials, presentation of the CS+ coterminated exactly with the presentation of the US (i.e., the "£" symbol [displayed above the CS] and the sound were presented from 5-6 s post CS onset).

Blocks of trials in acquisition consisted of 8 trials and in extinction consisted of 16 trials. At the end of each block, participants were asked to rate how much they liked the blue square and yellow square, where the scale ranged from 1 ("Don't Like") to 9 ("Do Like").

Participants were presented with two 9-point Likert scales at the end of the experiment. Participants were asked to rate: (1) the liking and (2) the arousal of the stimuli (i.e., the " $£$ " symbol and sound stimulus combined). These scales ranged from 1 (Liking: very negative; Arousal: calm) to 9 (Liking: very positive; Arousal: excited).

\section{3 | Procedure}

On the day of the experiment, participants were informed about the experimental procedures upon arrival at the laboratory. Participants were then seated in the testing booth and asked to complete a consent form and a series of questionnaires (see Section 2.4) on the computer screen.

After the questionnaires, physiological sensors were attached to the participants' left hand and left brow. Before the task began, participants were played the sound stimulus through the headphones, so they knew what to expect. Participants were instructed: (1) to maintain attention to the task by looking at the geometrical shapes, (2) to use the keyboard for the ratings, (3) that the " $£$ " symbol and sound represented a value of $£ 1$, and (4) that the $£ 5$ from taking part was separate from the money acquired during the task, and that they would receive the total amount of money at the end of the experiment. The conditioning task (see Section 2.2 above for details) was presented on a computer screen whilst skin conductance response, corrugator supercilii and liking ratings were recorded.

To maintain uncertainty, participants were not instructed about the CS-US contingency or the total amount of money that could be acquired during the task. The total amount of money that could be won during the task was fixed at $£ 5$. Therefore, all participants received a total $£ 10$ ( $£ 5$ from taking part and $£ 5$ acquired from the task) at the end of the experiment. 


\subsection{Measurements}

\subsection{1 | Questionnaires}

To assess intolerance of uncertainty and trait anxiety, we administered the Intolerance of Uncertainty Scale (IUS; Freeston et al., 1994) and State-Trait Inventory for Cognitive and Somatic Anxiety (STICSA; Ree et al., 2008). The IUS measure consists of 27 items that are rated on a 5-point Likert scale. The STICSA measure consists of 21 items that are rated on a 4-point Likert scale.

\subsubsection{Rating scoring}

Rating data were reduced for each participant by calculating their average responses for each experimental condition (Acquisition CS+; Acquisition CS-; Extinction Training CS+ Early; Extinction Training CS- Early; Extinction Training CS+ Late; Extinction Training CS- Late) using the E-Data Aid tool in E-Prime (Psychology Software Tools Ltd). For this measure, we had 58 participants with usable data.

\subsubsection{Skin conductance acquisition and scoring}

Identical to previous work (Morriss, 2019), physiological recordings were obtained using AD Instruments (AD Instruments Ltd) hardware and software. Electrodermal activity was measured with dry MLT118F stainless steel finger electrodes that were attached to the distal phalanges of the index and middle fingers of the left hand. A low constant-voltage AC excitation of $22 \mathrm{mVrms}$ at $75 \mathrm{~Hz}$ was passed through the electrodes, which was connected to a ML116 GSR Amp, and converted to DC before being digitized and stored. A PowerLab 26T Unit Model was used to amplify the skin conductance signal, which was digitized through a 16-bit A/D converter at $1,000 \mathrm{~Hz}$. The electrodermal signal was converted from volts to microSiemens using AD Instruments software (AD Instruments Ltd).

Skin conductance response onsets and offsets were marked using ADinstruments software (AD Instruments Ltd) and extracted using Matlab R2017a software (The MathWorks, Inc.). Skin conductance response onsets and offsets were assigned using a macro in ADinstruments that detected changes in slope within the derivative of the skin conductance channel. The skin conductance responses were then visually inspected to ensure the onsets and offsets were assigned correctly. If there was more than one SCR in the CS scoring window, the SCRs were scored separately, and the amplitude was averaged across SCRs for that CS scoring window $(0.03 \%$ of CS scoring windows). Skin conductance responses (SCR) were scored when there was an increase of skin conductance exceeding 0.03 microSiemens (Dawson, Schell, \& Filion, 2000). The amplitude of each response was scored as the difference between the onset and the maximum deflection prior to the signal flattening out or decreasing. SCR onsets and respective peaks were counted if the SCR onset was within 0.5-4 s (CS response) following CS onset (Bauer et al., 2020; Morriss et al., 2016). Trials with no discernible SCRs were scored as zero. The first paired CS+ trial was discarded due to the large orienting response confound. SCRs were then square root transformed to reduce skew and $z$-scored (within individuals) to control for interindividual differences in skin conductance responsiveness not due to the experimental manipulation (i.e., different skin physiology such as dryness/wetness of the skin; Ben-Shakhar, 1985). SCR magnitudes were calculated by averaging SCR values for each condition (Acquisition CS+; Acquisition CS-; Extinction Training CS+ Early; Extinction Training CS- Early; Extinction Training CS+ Late; Extinction Training CS- Late). Nonresponders were defined as those who responded to $10 \%$ or less of the total $\mathrm{CS}+$ and CS - trials across acquisition and extinction training (48 trials in total; Morriss et al., 2018; Xia et al., 2017; cf. for detailed commentary on alternative nonresponding criterions, see Lonsdorf et al., 2019). Using this criterion, eight nonresponders were excluded from the SCR analyses, leaving 50 participants with useable SCR data. ${ }^{1}$

\subsection{4 | Corrugator supercilii acquisition and scoring}

The protocol for corrugator acquisition and scoring was in line with previous research (Morriss, 2019) and recommendations (Tassinary \& Cacioppo, 2000). Facial electromyography measurement of the left corrugator supercilii was obtained by using a pair of 4-mm $\mathrm{Ag} / \mathrm{AgCl}$ bipolar surface electrodes connected to the ML138 Bio Amp. The bipolar surface electrodes were placed approximately $15 \mathrm{~mm}$ apart on the left brow. The reference electrode was a singular 8-mm $\mathrm{Ag} / \mathrm{AgCl}$ electrode, placed upon the middle of the forehead, and connected to the ML138 Bio Amp. Before placing the sensors, the skin site was slightly abraded with isopropyl alcohol skin prep pads to reduce skin impedance to an acceptable level (below $20 \mathrm{k} \Omega$ ). EMG was sampled at 1,000 Hz. A high-pass filter of $20 \mathrm{~Hz}$ was applied to the raw EMG online (Solnik et al., 2008). The EMG were root mean squared offline (Fridlund \& Cacioppo, 1986).

Corrugator supercilii activity was extracted using R software (R Core Team, 2014). Corrugator supercilii activity was averaged for each 1,000 ms window following CS onset, resulting in five windows of $1,000 \mathrm{~ms}$ each. These data were baseline

${ }^{1} \mathrm{SCR}$ results were slightly weaker but similar when including the nonresponders: acquisition [stimulus: $F(1,56)=1.707, p=.197$ ] and extinction [stimulus: $F(1,207.063)=3.837, p=.051$ ] 
corrected by subtracting 2,000 ms preceding each CS onset from a blank screen (similar to procedures used by Morriss, 2019). Corrugator supercilli activity was $z$-scored (within individuals) to control for interindividual differences in corrugator supercilli activity not due to the experimental manipulation (i.e., different skin types or muscle size; Ben-Shakhar, 1985). Corrugator supercilii trials were averaged per condition and second window (Acquisition CS+; Acquisition CS-; Extinction Training CS+ Early; Extinction Training CS- Early; Extinction Training CS+ Late; Extinction Training CS- Late).

For the corrugator supercilii data, there was a recording error for 1 participant, thus, leaving 57 participants with useable corrugator supercilii data.

\section{5 | Analyses}

The analyses were conducted using the mixed procedure in SPSS 24.0 (SPSS, Inc). We conducted separate MLMs for SCR magnitude, corrugator supercilii activity and liking ratings during acquisition and extinction training. For SCR magnitude and liking ratings during the acquisition training phase we entered Stimulus (CS+, CS-) at level 1 and individual subjects at level 2. For SCR magnitude and liking ratings during the extinction training phase we entered Stimulus (CS+, CS-) and Time (Early: first $8 \mathrm{CS}+/ \mathrm{CS}-$ trials, Late: last $8 \mathrm{CS}+/ \mathrm{CS}-$ trials) at level 1 and individual subjects at level 2. For corrugator supercilii activity, an additional factor of Second (time bins: 1, 2, 3, 4, 5) at level 1 was included in the MLMs. We included individual difference predictor variables (IU and STICSA) in the MLMs. In all models, we used a diagonal covariance matrix for level 1. Random effects included a random intercept for each individual subject, where a variance components covariance structure was used. Fixed effects included Stimulus and Time. We used a maximum likelihood estimator for the MLMs.

The IUS and STICSA covariates were entered separately. If there was a significant interaction with one of the predictor variables (IUS, STICSA), then we conducted a further MLM with both predictor variables entered to test specificity. Based on previous work (Morriss, 2019), we expected such specificity for IUS, but we explored interactions with STICSA, given findings with trait anxiety in the conditioning literature (Lonsdorf \& Merz, 2017). If a significant interaction was observed with IUS (or STICSA), we performed follow-up pairwise comparisons on the estimated marginal means of the relevant conditions estimated at specific IUS values of + or $-1 S D$ of mean IUS, adjusted for STICSA (or IUS; Morriss, 2019; Morriss, Saldarini, \& Van Reekum, 2019).

\section{3 | RESULTS}

For descriptive statistics, see Table 1.

\section{1 | Questionnaires}

The self-reported anxiety measures had excellent internal reliability: IUS $(M=63.87, S D=20.06$, range $=30-112$, $\alpha=0.94)$; STICSA $(M=38.43, S D=9.88$, range $=24-66$, $\alpha=0.89)$. IUS was positively significantly correlated with STICSA, $r(56)=0.745, p<.001$.

\section{2 | Ratings}

The " $£$ " symbol and sound stimulus was on average rated as moderately positive $(M=7.39, S D=1.58$, range $3-9$, where $1=$ very negative and $9=$ very positive) and moderately arousing $(M=6.36, S D=2.10,1-9$, range where $1=$ calm and $9=$ excited).

During acquisition training participants reported greater liking ratings of the $\mathrm{CS}+$, compared to the $\mathrm{CS}-$ [stimulus: $F(1,115.186)=47.372, p<.001$; see Table 1, Figure 1; Figure S1]. No significant interactions with IUS or STICSA

T A B L E 1 Summary of means $(S D)$ for each dependent measure as a function of condition (CS+ and CS-), separately for acquisition, early extinction, and late extinction

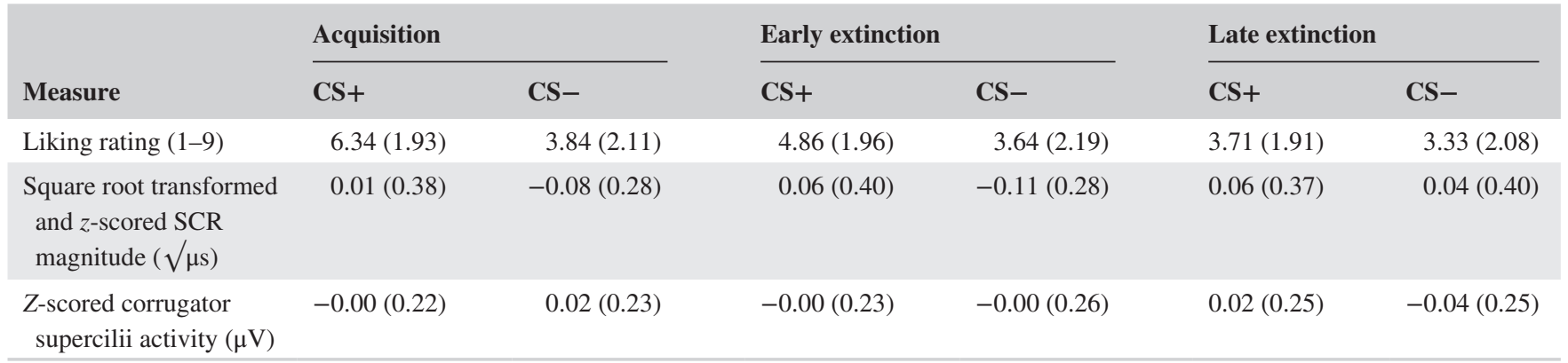

Note: Liking ratings from 1 to 9 , where 1 is like and 9 is dislike; SCR magnitude $(\sqrt{ } \mu \mathrm{S})$, square root transformed and $z$-scored skin conductance magnitude measured in microSiemens; Corrugator supercilii activity $(\mu \mathrm{V}), z$-scored corrugator supercilii activity measured in microVolts. 

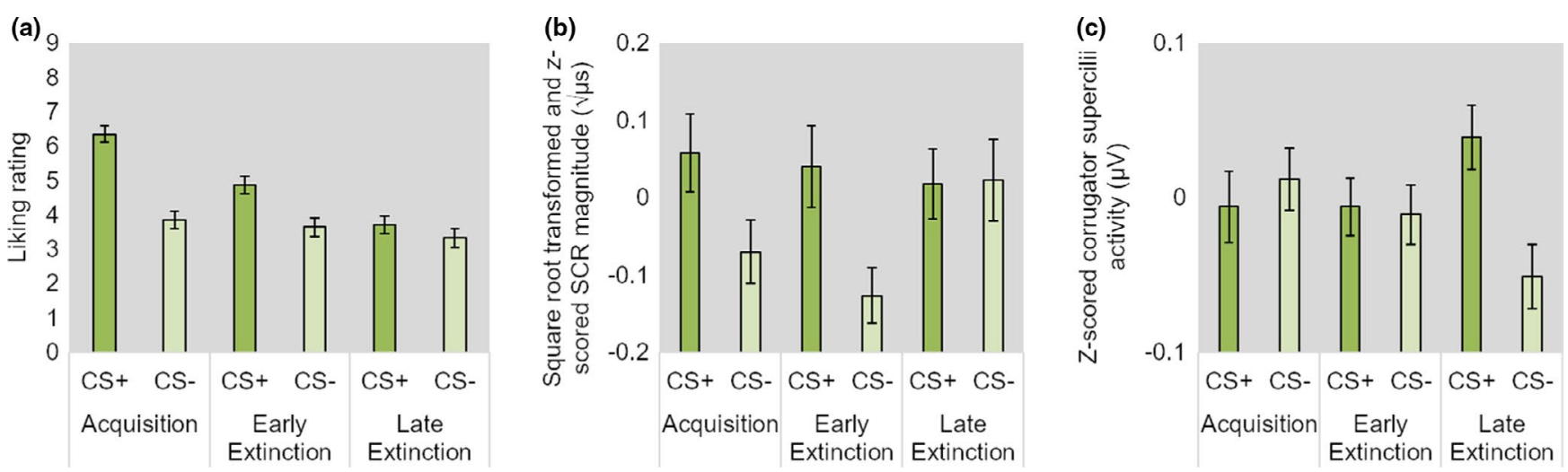

F I G U R E 1 Bar graphs depicting mean (a) liking ratings, (b) SCR magnitude, (c) for each stimulus type during each experimental phase of the Pavlovian reward conditioning task. Error bars represent standard error. Liking ratings, $1=$ don't like, $9=$ do like. Square root transformed and $z$-transformed SCR magnitude $(\mu \mathrm{S})$, skin conductance magnitude measured in microSiemens. Z-scored corrugator supercilii activity $(\mu \mathrm{V})$, measured in microVolts

were observed for the ratings during acquisition training, $\max F=1.332$.

During extinction training, participants reported greater liking ratings for the $\mathrm{CS}+$, compared to the $\mathrm{CS}-[$ Stimulus: $F(1$, 170.616) $=16.327, p<.001$; see Table 1; Figure 1]. Ratings of liking dropped over time [Time: $F(1,170.616)=13.639$, $p<.001$; stimulus $\times$ time: $F(1,170.616)=4.533, p=.035]$ Follow-up pairwise comparisons revealed that participants reported: (1) greater liking ratings for the CS+ versus $\mathrm{CS}-$ during early extinction training, $p<.001$, but not during late extinction training, $p=.165$; (2) greater liking ratings of the CS+ during early, compared to late extinction training, $p<.001$; and (3) smaller liking ratings of the CS - during early and late extinction training, $p=.295$. No significant interactions with IUS or STICSA were found for the ratings during extinction training, $\max F=2.755$.

\subsection{SCR}

During acquisition training, SCRs were larger to the CS+, compared to the CS-; however, this pattern was not significant [Stimulus: $F(1,50)=2.197, p=.145$; see Table 1 , Figure 1; Figure S1]. No significant interactions with IUS or STICSA were observed for SCRs during acquisition training, $\max F=0.431$.

During extinction training, SCRs were significantly larger to the $\mathrm{CS}+$, versus the $\mathrm{CS}-[$ Stimulus: $F(1,187.817)=4.012$, $p=.047$; see Table 1, Figure 1; Figure S1]. No other significant effects of time or stimulus $\times$ time, or interactions with IUS and STICSA were observed, $\max F=2.686 .^{2}$

\footnotetext{
${ }^{2}$ Square root transformed SCR (without $z$-scoring) yielded weaker effects for acquisition [stimulus: $F(1,50)=0.297, p=.588$ ]. However, square root transformed SCR (without z-scoring) revealed similar results for extinction [Stimulus: $F(1,142.650)=4.542, p=.035$ ]. For square root transformed SCR, there were no significant interactions with IU or STICSA, max $F=3.046$
}

\subsection{Corrugator supercilii activity}

During acquisition training, we did not observe a significant difference for corrugator supercilii activity to the $\mathrm{CS}+$, versus the CS- [stimulus: $F(1,471.367)=1.541, p=.215$; see Table 1]. There was a significant interaction between IUS and the corrugator supercilii during acquisition; however, these results were likely spurious (see the Supporting Information).

We observed no significant differences in corrugator supercilii activity to the $\mathrm{CS}+$, versus the $\mathrm{CS}-$ during extinction training nor a significant interaction with time [stimulus: $F(1,1,042.553)=2.964, p=.085$; stimulus $\times$ time: $F(1$, $1,042.553)=3.086, p=.079$; see Table 1; Figure 1]. No significant interactions with IUS or STICSA were observed for the corrugator supercilii during extinction training, max $F=1.136$.

\section{4 | DISCUSSION}

In the current study, we examined the role of self-reported IU in reward acquisition and extinction. Typical patterns of reward acquisition were observed for the liking ratings. However, there was very little evidence for reward acquisition in the SCR and corrugator supercilii measures. IU was not related to any measures during the acquisition or extinction training phases. Such results suggest that the Pavlovian reward conditioning task used in this experiment was not sufficient for evoking a reliable conditioned response, and that further research is needed with optimized experimental designs to test whether IU modulates the extinction of reward.

Similar to aversive conditioning, (Lonsdorf et al., 2017), appetitive conditioned responses can be elicited by a CS when this stimulus predicts an appetitive US, regardless if this is a primary (i.e., food; Andreatta et al., 2015, Ebrahimi et al., 2019; Wardle et al., 2018) or a secondary (i.e., money, 
Kruse et al., 2017; Tapia León et al., 2018; Tapia Leon et al., 2019) reward. In line with previous work, reward acquisition was observed via liking ratings to the $\mathrm{CS}+$ versus $\mathrm{CS}-$ cues (Andreatta \& Pauli, 2015, 2019; Ebrahimi et al., 2019; Kruse et al., 2017, 2018; Tapia León et al., 2019; Wardle et al., 2018). However, reward acquisition was not observed via SCRs and the corrugator supercilii. Although patterns of SCR and corrugator supercilii responding were in the expected direction (i.e., greater SCR and less corrugator supercilii activity to the CS+ versus CS- cues (see Figure S1; Wardle et al., 2018). It is possible that the conditioned response is slower to emerge for uninstructed Pavlovian reward conditioning, compared to instructed Pavlovian reward conditioning (Tapia Leon et al., 2019) and uninstructed instrumental reward conditioning (Kruse et al., 2017, 2018, 2020).

Furthermore, typical patterns of reward extinction were observed in the liking ratings, whereby liking ratings were larger to the CS+ versus CS- cues during early extinction training, compared to late extinction training (Andreatta \& Pauli, 2015; Ebrahimi et al., 2019; Kruse et al., 2017, 2020). Interestingly, SCRs were larger overall to the $\mathrm{CS}+$, compared to the CS- throughout extinction training. We would have expected this difference in SCRs to diminish across extinction training (see Figure S1). The discrepancy between the psychophysiology results from our study and previous research on appetitive conditioning (Andreatta \& Pauli, 2015, 2019; Ebrahimi et al., 2019; Kruse et al., 2017, 2018; Tapia León et al., 2018, 2019; Wardle et al., 2018) may be due to design details such as the number of trials presented during acquisition training, and differences in motivation and incentive (i.e., other studies have made participants hungry before testing or have made them learn to press a button to receive reward).

The hypothesis was that if IU-related effects during extinction are driven by the arousingness of an uncertain stimulus, then higher IU, relative to lower IU, would be associated with larger conditioned responding to CS+ versus CS- during extinction training. However, IU was not associated with any of the rating or physiological measures during reward extinction training. IU-related effects may have not been observed in the current study because boundary conditions for reward acquisition were not met (i.e., a reliable conditioned response was not found across measures). For example, perhaps, IU-related effects would have been observed during the extinction of reward if the rewarding stimulus was more arousing (i.e., larger monetary rewards), if participants had to actively engage (i.e., pressing a button to receive the monetary reward) or if the rewarding stimulus was motivationally relevant in relation to a threat or loss to the self (i.e., money when poorer, food when hungry, and substances such as nicotine or alcohol when addicted). Further evidence is warranted to make stronger conclusions on the role of IU in reward extinction, compared to threat extinction (Dunsmoor et al., 2015; Morriss, 2019; Morriss \& van Reekum, 2019).

The study had a few strengths and weaknesses. Firstly, to be comparable with previous research on IU and uninstructed Pavlovian conditioned threat (Morriss et al., 2015, Morriss, Christakou, et al., 2016, Morriss, Macdonald, et al., 2016), the current study used an uninstructed Pavlovian conditioned reward (i.e., to receive the reward no action is required). However, as far as we are aware only one study to date has used monetary reward with an uninstructed Pavlovian design (Tapia Leon et al., 2018), and the majority of research has used uninstructed instrumental designs (Kruse et al., 2018, 2020; Kruse et al., 2017; i.e., to receive the reward an action needs to be made). Thus, the current study provides important information on Pavlovian conditioned reward generally and in relation to IU but there is limited research to directly compare against. Secondly, in the current study we did not assess contingency awareness, which may have been beneficial for further explaining the pattern of results generally and in relation to IU.

In conclusion, IU was not related to any measure during the reward acquisition or extinction training phases. These initial null results, potentially due to boundary conditions not being met, suggest that further research is needed with optimized reward conditioning designs to clarify the role of IU in the extinction of reward. Future research on the role of IU in the extinction of reward may benefit from varying the levels of uncertainty, reward and motivation/incentive.

\section{ACKNOWLEDGEMENTS}

This research was supported by (1) a NARSAD Young Investigator Grant from the Brain \& Behavior Research Foundation (27567) and an ESRC New Investigator Grant (ES/R01145/1) awarded to Jayne Morriss.

\section{CONFLICT OF INTEREST}

The authors state no conflict of interest.

\section{AUTHOR CONTRIBUTIONS}

J.M., T.B.L. and M.A. designed the experiment. J.M. wrote the manuscript and analyzed the data. N.B collected the data and coded scripts for the extraction of data. T.B.L. and M.A. edited the manuscript. J.M., T.B.L. and M.A. revised the manuscript.

\section{PEER REVIEW}

The peer review history for this article is available at https:// publons.com/publon/10.1111/ejn.15173.

\section{DATA AVAILABILITY STATEMENT}

To access the data, please visit the following Open Science Framework link https://osf.io/uv268/. 


\section{ORCID}

Jayne Morriss (iD https://orcid.org/0000-0002-7928-9673

Marta Andreatta (D) https://orcid.org/0000-0002-1217-8266

\section{REFERENCES}

Andreatta, M., \& Pauli, P. (2015). Appetitive vs. aversive conditioning in humans. Frontiers in Behavioral Neuroscience, 9, 128.

Andreatta, M., \& Pauli, P. (2019). Generalization of appetitive conditioned responses. Psychophysiology, e13397. https://doi. org/10.1111/psyp.13397

Bauer, E. A., MacNamara, A., Sandre, A., Lonsdorf, T. B., Weinberg, A., Morriss, J., \& Van Reekum, C. M. (2020). Intolerance of uncertainty and threat generalization: A replication and extension. Psychophysiology, e13546. https://doi.org/10.1111/psyp.13546

Ben-Shakhar, G. (1985). Standardization within individuals: A simple method to neutralize individual differences in skin conductance. Psychophysiology, 22(3), 292-299. https://doi.org/10.1111/ j.1469-8986.1985.tb01603.x

Bouton, M. E. (2002). Context, ambiguity, and unlearning: Sources of relapse after behavioral extinction. Biological Psychiatry, 52(10), 976-986. https://doi.org/10.1016/S0006-3223(02)01546-9

Carleton, R. N. (2016a). Fear of the unknown: One fear to rule them all? Journal of Anxiety Disorders, 41, 5-21. https://doi.org/10.1016/j. janxdis.2016.03.011

Carleton, R. N. (2016b). Into the unknown: A review and synthesis of contemporary models involving uncertainty. Journal of Anxiety Disorders, 39, 30-43. https://doi.org/10.1016/j.janxd is.2016.02.007

Carleton, R. N., Duranceau, S., Shulman, E. P., Zerff, M., Gonzales, J., \& Mishra, S. (2016). Self-reported intolerance of uncertainty and behavioural decisions. Journal of Behavior Therapy and Experimental Psychiatry, 51, 58-65. https://doi.org/10.1016/j. jbtep.2015.12.004

Chin, B., Nelson, B. D., Jackson, F., \& Hajcak, G. (2016). Intolerance of uncertainty and startle potentiation in relation to different threat reinforcement rates. International Journal of Psychophysiology, 99, 79-84. https://doi.org/10.1016/j.ijpsycho.2015.11.006

Craske, M. G., Treanor, M., Conway, C. C., Zbozinek, T., \& Vervliet, B. (2014). Maximizing exposure therapy: An inhibitory learning approach. Behaviour Research and Therapy, 58, 10-23. https://doi. org/10.1016/j.brat.2014.04.006

Dawson, M. E., Schell, A. M., \& Filion, D. L. (2000). The electrodermal system. In J. T. Cacioppo, L. G. Tassinary, \& G. G. Berntson (Eds.), Handbook of physiology (2nd ed., pp. 200-223). Cambridge University Press.

Dunsmoor, J. E., Campese, V. D., Ceceli, A. O., LeDoux, J. E., \& Phelps, E. A. (2015). Novelty-facilitated extinction: Providing a novel outcome in place of an expected threat diminishes recovery of defensive responses. Biological Psychiatry, 78(3), 203-209. https:// doi.org/10.1016/j.biopsych.2014.12.008

Ebrahimi, C., Koch, S. P., Pietrock, C., Fydrich, T., Heinz, A., \& Schlagenhauf, F. (2019). Opposing roles for amygdala and vmPFC in the return of appetitive conditioned responses in humans. Translational Psychiatry, 9(1), 1-12. https://doi.org/10.1038/s4139 8-019-0482-x

Freeston, M. H., Rhéaume, J., Letarte, H., Dugas, M. J., \& Ladouceur, R. (1994). Why do people worry? Personality and Individual Differences, 17(6), 791-802. https://doi. org/10.1016/0191-8869(94)90048-5
Fridlund, A. J., \& Cacioppo, J. T. (1986). Guidelines for human electromyographic research. Psychophysiology, 23(5), 567-589. https:// doi.org/10.1111/j.1469-8986.1986.tb00676.x

Gorka, S. M., Nelson, B. D., Phan, K. L., \& Shankman, S. A. (2016). Intolerance of uncertainty and insula activation during uncertain reward. Cognitive, Affective, \& Behavioral Neuroscience, 16(5), 929 939. https://doi.org/10.3758/s13415-016-0443-2

Grös, D. F., Antony, M. M., Simms, L. J., \& McCabe, R. E. (2007). Psychometric properties of the State-Trait Inventory for Cognitive and Somatic Anxiety (STICSA): Comparison to the State-Trait Anxiety Inventory (STAI). Psychological Assessment, 19(4), 369. https://doi.org/10.1037/1040-3590.19.4.369

Kesby, A., Maguire, S., Brownlow, R., \& Grisham, J. R. (2017). Intolerance of uncertainty in eating disorders: An update on the field. Clinical Psychology Review, 56, 94-105. https://doi.org/10.1016/j. cpr.2017.07.002

Koskina, A., Campbell, I. C., \& Schmidt, U. (2013). Exposure therapy in eating disorders revisited. Neuroscience \& Biobehavioral Reviews, 37(2), 193-208. https://doi.org/10.1016/j.neubiorev.2012.11.010

Kruse, O., Klein, S., Tapia León, I., Stark, R., \& Klucken, T. (2020). Amygdala and nucleus accumbens involvement in appetitive extinction. Human Brain Mapping, 41(7). https://doi.org/10.1002/ hbm. 24915

Kruse, O., Tapia León, I., Stalder, T., Stark, R., \& Klucken, T. (2018). Altered reward learning and hippocampal connectivity following psychosocial stress. NeuroImage, 171, 15-25. https://doi. org/10.1016/j.neuroimage.2017.12.076

Kruse, O., Tapia León, I., Stark, R., \& Klucken, T. (2017). Neural correlates of appetitive extinction in humans. Social Cognitive and Affective Neuroscience, 12(1), 106-115. https://doi.org/10.1093/scan/nsw157

Lonsdorf, T. B., Klingelhöfer-Jens, M., Andreatta, M., Beckers, T., Chalkia, A., Gerlicher, A., \& Sjouwerman, R. (2019). Navigating the garden of forking paths for data exclusions in fear conditioning research. Elife, 8, e52465.

Lonsdorf, T. B., \& Merz, C. J. (2017). More than just noise: Interindividual differences in fear acquisition, extinction and return of fear in humans - Biological, experiential, temperamental factors, and methodological pitfalls. Neuroscience \& Biobehavioral Reviews, 80, 703-728. https://doi.org/10.1016/j.neubiorev.2017.07.007

Lonsdorf, T. B., Menz, M. M., Andreatta, M., Fullana, M. A., Golkar, A., Haaker, J., ... Merz, C. J. (2017). Don’t fear 'fear conditioning': Methodological considerations for the design and analysis of studies on human fear acquisition, extinction, and return of fear. Neuroscience \& Biobehavioral Reviews, 77, 247-285.

Lucas, K., Luck, C. C., \& Lipp, O. V. (2018). Novelty-facilitated extinction and the reinstatement of conditional human fear. Behaviour Research and Therapy, 109, 68-74. https://doi.org/10.1016/j.brat.2018.08.002

Luhmann, C. C., Ishida, K., \& Hajcak, G. (2011). Intolerance of uncertainty and decisions about delayed, probabilistic rewards. Behavior Therapy, 42(3), 378-386. https://doi.org/10.1016/j. beth.2010.09.002

Marissen, M. A., Franken, I. H., Blanken, P., van den Brink, W., \& Hendriks, V. M. (2007). Cue exposure therapy for the treatment of opiate addiction: Results of a randomized controlled clinical trial. Psychotherapy and Psychosomatics, 76(2), 97-105. https://doi. org/10.1159/000097968

McEvoy, P. M., \& Mahoney, A. E. (2012). To be sure, to be sure: Intolerance of uncertainty mediates symptoms of various anxiety disorders and depression. Behavior Therapy, 43(3), 533-545. https://doi.org/10.1016/j.beth.2011.02.007 
Morriss, J. (2019). What do I do now? Intolerance of uncertainty is associated with discrete patterns of anticipatory physiological responding to different contexts. Psychophysiology, e13396. https:// doi.org/10.1111/psyp.13396

Morriss, J., Chapman, C., Tomlinson, S., \& Van Reekum, C. M. (2018). Escape the bear and fall to the lion: The impact of avoidance availability on threat acquisition and extinction. Biological Psychology, 138, 73-80. https://doi.org/10.1016/j.biopsycho.2018.08.017

Morriss, J., Christakou, A., \& Van Reekum, C. M. (2015). Intolerance of uncertainty predicts fear extinction in amygdala-ventromedial prefrontal cortical circuitry. Biology of Mood \& Anxiety Disorders, 5(1), 1. https://doi.org/10.1186/s13587-015-0019-8

Morriss, J., Christakou, A., \& Van Reekum, C. M. (2016). Nothing is safe: Intolerance of uncertainty is associated with compromised fear extinction learning. Biological Psychology, 121, 187-193. https:// doi.org/10.1016/j.biopsycho.2016.05.001

Morriss, J., Macdonald, B., \& van Reekum, C. M. (2016). What is going on around here? Intolerance of uncertainty predicts threat generalization. PLoS One, 11(5), e0154494. https://doi.org/10.1371/journ al.pone.0154494

Morriss, J., Saldarini, F., Chapman, C., Pollard, M., \& van Reekum, C. M. (2019). Out with the old and in with the new: The role of intolerance of uncertainty in reversal of threat and safety. Journal of Experimental Psychopathology, 10(1). https://doi. org/10.1177/2043808719834451

Morriss, J., Saldarini, F., \& Van Reekum, C. M. (2019). The role of threat level and intolerance of uncertainty in extinction. International Journal of Psychophysiology, 142, 1-9. https://doi.org/10.1016/j. ijpsycho.2019.05.013

Morriss, J., \& van Reekum, C. M. (2019). I feel safe when i know: Contingency instruction promotes threat extinction in high intolerance of uncertainty individuals. Behaviour Research and Therapy, 116, 111-118. https://doi.org/10.1016/j.brat.2019.03.004

Morriss, J., Wake, S., Lindner, M., McSorley, E., \& Dodd, H. (2020). How many times do I need to see to believe? The impact of intolerance of uncertainty and exposure experience on safetylearning and retention in young adults. International Journal of Psychophysiology, 153, 8-17. https://doi.org/10.1016/j.ijpsy cho.2020.04.012

Nelson, B. D., Kessel, E. M., Jackson, F., \& Hajcak, G. (2016). The impact of an unpredictable context and intolerance of uncertainty on the electrocortical response to monetary gains and losses. Cognitive, Affective, \& Behavioral Neuroscience, 16(1), 153-163. https://doi. org/10.3758/s13415-015-0382-3

Nelson, B. D., Shankman, S. A., \& Proudfit, G. H. (2014). Intolerance of uncertainty mediates reduced reward anticipation in major depressive disorder. Journal of Affective Disorders, 158, 108-113. https://doi.org/10.1016/j.jad.2014.02.014

Peugh, J. L. (2010). A practical guide to multilevel modeling. Journal of School Psychology, 48(1), 85-112. https://doi.org/10.1016/j. jsp.2009.09.002

Ree, M. J., French, D., MacLeod, C., \& Locke, V. (2008). Distinguishing cognitive and somatic dimensions of state and trait anxiety: Development and validation of the State-Trait Inventory for Cognitive and Somatic Anxiety (STICSA). Behavioural and Cognitive Psychotherapy, 36(3), 313-332. https://doi.org/10.1017/ S1352465808004232

Sjouwerman, R., Scharfenort, R., \& Lonsdorf, T. B. (2020). Individual differences in fear acquisition: Multivariate analyses of different emotional negativity scales, physiological responding, subjective measures, and neural activation. Scientific Reports, 10, 15283. https://doi.org/10.1038/s41598-020-72007-5

Solnik, S., DeVita, P., Rider, P., Long, B., \& Hortobágyi, T. (2008). Teager-Kaiser Operator improves the accuracy of EMG onset detection independent of signal-to-noise ratio. Acta of Bioengineering and biomechanics/Wroclaw University of Technology, 10(2), 65.

Tanovic, E., Gee, D. G., \& Joormann, J. (2018). Intolerance of uncertainty: Neural and psychophysiological correlates of the perception of uncertainty as threatening. Clinical Psychology Review, 60, 8799. https://doi.org/10.1016/j.cpr.2018.01.001

Tanovic, E., Hajcak, G., \& Joormann, J. (2018). Hating waiting: Individual differences in willingness to wait in uncertainty. Journal of Experimental Psychopathology, 9(1). https://doi.org/10.1177/20438 08718778982

Tapia León, I., Kruse, O., Stalder, T., Stark, R., \& Klucken, T. (2018). Neural correlates of subjective CS/UCS association in appetitive conditioning. Human Brain Mapping, 39(4), 1637-1646.

Tapia León, I., Kruse, O., Stark, R., \& Klucken, T. (2019). Relationship of sensation seeking with the neural correlates of appetitive conditioning. Social Cognitive and Affective Neuroscience, 14(7), 769775. https://doi.org/10.1093/scan/nsz046

Tassinary, L. G., \& Cacioppo, J. T. (2000). The skeletomotor system: Surface electromyography (J. T. Cacioppo, L. G. Tassinary, \& G. G. Berntson (Eds.), 2nd edn., pp. 163-199). New York: Cambridge University Press.

van den Akker, K., Nederkoorn, C., \& Jansen, A. (2017). Electrodermal responses during appetitive conditioning are sensitive to contingency instruction ambiguity. International Journal of Psychophysiology, 118, 40-47. https://doi.org/10.1016/j.ijpsy cho.2017.06.004

Wake, S., Morriss, J., Johnstone, T., van Reekum, C. M., \& Dodd, H. (2021). Intolerance of uncertainty, and not social anxiety, is associated with compromised extinction of social threat. Behaviour Research and Therapy, 139. https://doi.org/10.1016/j. brat.2021.103818

Wake, S., van Reekum, C. M., Dodd, H., \& Morriss, J. (2020). The impact of intolerance of uncertainty and cognitive behavioural instructions on safety learning. Cognitive Therapy and Research, 44, 931-942. https://doi.org/10.1007/s10608-020-10113-4

Wardle, M. C., Lopez-Gamundi, P., \& Flagel, S. B. (2018). Measuring appetitive conditioned responses in humans. Physiology \& Behavior, 188, 140-150. https://doi.org/10.1016/j.physbeh.2018.02.004

Xia, W., Dymond, S., Lloyd, K., \& Vervliet, B. (2017). Partial reinforcement of avoidance and resistance to extinction in humans. Behaviour Research and Therapy, 96, 79-89. https://doi.org/10.1016/j. brat.2017.04.002

\section{SUPPORTING INFORMATION}

Additional supporting information may be found online in the Supporting Information section.

How to cite this article: Morriss J, Biagi N, Lonsdorf $\mathrm{TB}$, Andreatta $\mathrm{M}$. The role of intolerance of uncertainty in the acquisition and extinction of reward. Eur $J$ Neurosci. 2021;53:3063-3071. https://doi.org/10.1111/ ejn. 15173 